\title{
Integrating Technology in the Teaching Process For Better Learning Outcomes
}

\author{
Abas Hadawey, Robin Jones, Raveendran Sundararajan and Shatha \\ Haddowe \\ London South Bank University, United Kingdom
}

\begin{abstract}
Considerable study has been conducted on the teaching and learning of mathematics for engineering undergraduates. This paper describes preliminary research results of technology integrated teaching processes to enhance the teaching and learning process. The theory under investigation is that by taking advantage of developments in technology combined with appropriate learning theory, students should be exposed to the topic through different delivery methods in order for them to 'digest' the subject matter. This approach is generally referred to as Technology Enhanced Learning (TEL) and is increasingly becoming an expectation from higher education students.
\end{abstract}

The aim of this investigation was to implement a technology in the teaching process, to facilitate the learning and understanding development of the students and encourage the students to participate with module contents outside the classroom. Also to determine the apparent effectiveness of the application of the technology to assist with the learning process.

The application of the suggested TEL investigation involved filming the solutions of the weekly tutorial questions of Advanced Engineering Mathematics and Modelling (level 5), uploading them on-line to Moodle VLE. Students were given access to these video files as an extra teaching tool thereby allowing students to review the content at their own pace, as the videos became available. The video tutorials included recordings of problem solving by hand writing the solutions with complimentary voice instruction. The study used qualitative methods and worked in partnership with 90 undergraduate students to explore their experiences of using the video tutorials

The collected data revealed that around $85 \%$ of students felt that using the video tutorials (VT) in the tutorial sessions helped them learn the course materials, feel more engaged, confident with how to deal with the topic, support the independent learning, assessing their learning and prepare them for the exam.

Keywords: TEL, learning styles, video tutorial, teaching engineering mathematics.

\section{INTRODUCTION:}

Higher Education institutions must develop effective techniques in order to provide outstanding education and also respond to the increasing demand for meaningful and relevant teaching. Integrating technology in the teaching process to enhance the learning process is one method that can contribute positively to the teaching and learning process. Therefore, the video tutorials (besides classroom lectures, MS PowerPoint-slides notes, handouts and tutorials) are another practical and technically possible means of achieving this.

A report was produced by [1], displaying a research on the relationship between the use of technology and students' educational achievement as a focal point. The review of the research appeared to suggest cautious optimism for a positive relationship. Using an experimental design, [2] found that students across levels appear to enjoy the use of technology in their classes, also showed the significant percentile increases in performance on achievement tests when instruction was computer based. In 2002, [4] discussed the potential benefits of problem based video podcasts but did not properly study their impact on students learning. Later in (2004), [3] reported that students had positive attitudes towards the use of video podcasting in an undergraduate level of education. Also it was stated that the key benefits of using accessible viewing of video to support the teaching process include improved learning and study habits [6]. Technology can help, not just by encouraging people to work together, but by helping profit from collaboration, to learn about things that would be difficult to learn alone. Advanced pedagogy is required if today's learners are to gain the abilities necessary to succeed in tomorrow's increasingly interconnected and technological world, [5].

The initial implementation of the suggested TEL project involves of filming the solution of the 


\section{International Conference on Advanced Research in Teaching and Education}

weekly tutorial questions, uploading them to Moodle VLE. Students can access these files as an extra teaching tool. The aims of this project was to implement a technology in the teaching process, in order to create an environment that encourages students to participate in a module outside the classroom, and to improve students' engagement or time spent on learning to achieve a better learning performance. Second year module (level 5) Advanced Engineering Mathematics and Modelling (ENG_5_410) was used as a starting point for the TEL project, 90 students were taking part in the evaluation of the project.

\section{RESEARCH METHOD AND ASSESSMENT}

The schedule of the project was prearranged during semester 1 of the current academic year 2017-2018, over 13 weeks of teaching the solutions of the weekly tutorial questions were filmed and uploaded to the Moodle VLE on a weekly basis. The video tutorial showed solving problems using hand writing, supported by voice instructions. The purpose of evaluation for the suggested TEL was to check whether the objectives are met and also to show the impact of the suggested TEL on the learning process. This was done through a specially designed questionnaire which also contributed to assess the effectiveness of the suggested TEL activity on the learning processes. Moreover, a section was adding to the questionnaire, so student can provide any suggestion to make the TEL more useful (from student perspective).

\section{RESULTS AND DISCUSSION Student}

Learning Predilections: Data showed that, little variation in the learning styles categories that students consider to learn (Figure 1). However, students' feedback for learning preferences showed that around $80 \%$ of the student's learning preferences, their selections were based on visual, written or spoken explanation, solving problems/using mathematical relationships and step aby step approach to get understanding as a direction of learning.

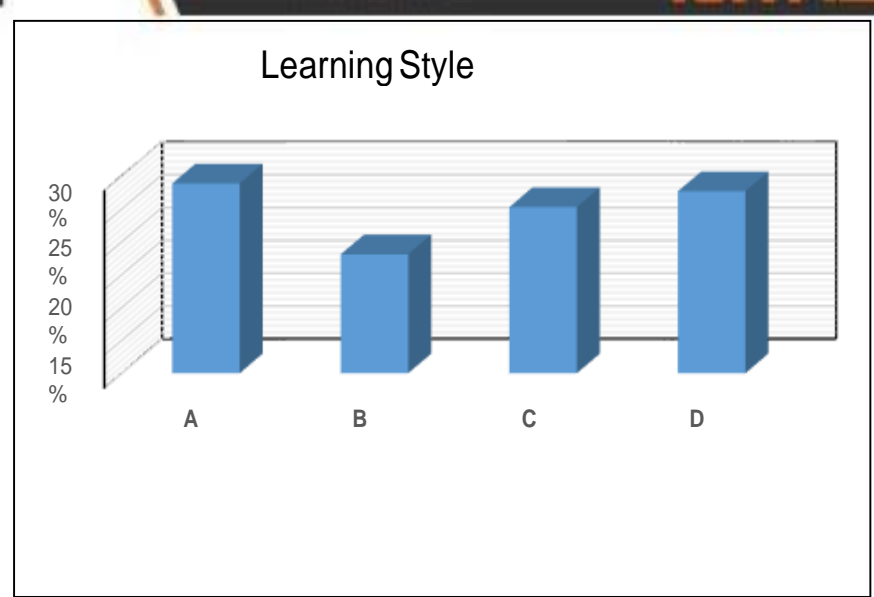

Figure 1: Student's Learning Preferences

A: Visual\& written or spoken explanation

B: Solving problems\& prefer to discover possibilities and relationships

C: Understand by applying the knowledge or explaining to others

D: Step by step approach to gain understanding

Moreover, the collected data exposed that around $65 \%$ of the students spent more than $40 \%$ of their revision time on watching the video tutorials as revision material (Figure 2). The remaining 35\% of the students reported that they spent between 10 to $30 \%$ of their revision time on watching the video tutorials as revision material.

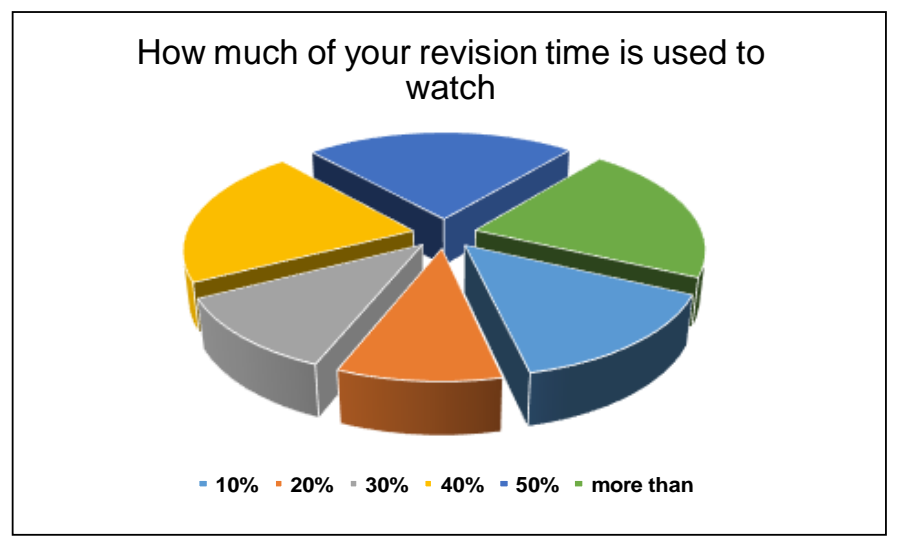

Figure 2: Revision Time Spent on Watching VT

\section{Impact of the suggested technology on the learning} outcomes: the impact of the video tutorials on the learning outcomes was assessed through different types of questions, Figure 3 (total of responses of Good and Excellent was considered as positive response) at the end of week 12 teaching, around $85 \%$ (average positive responses) of students felt that using the video tutorials helped them learn the course materials, more engagement, confident of how to deal with topic. Also the students felt that the 


\section{International Conference on Advanced Research in Teaching and Education}

VT supported their independent learning and also the VT was used as an assessment tool for assessing
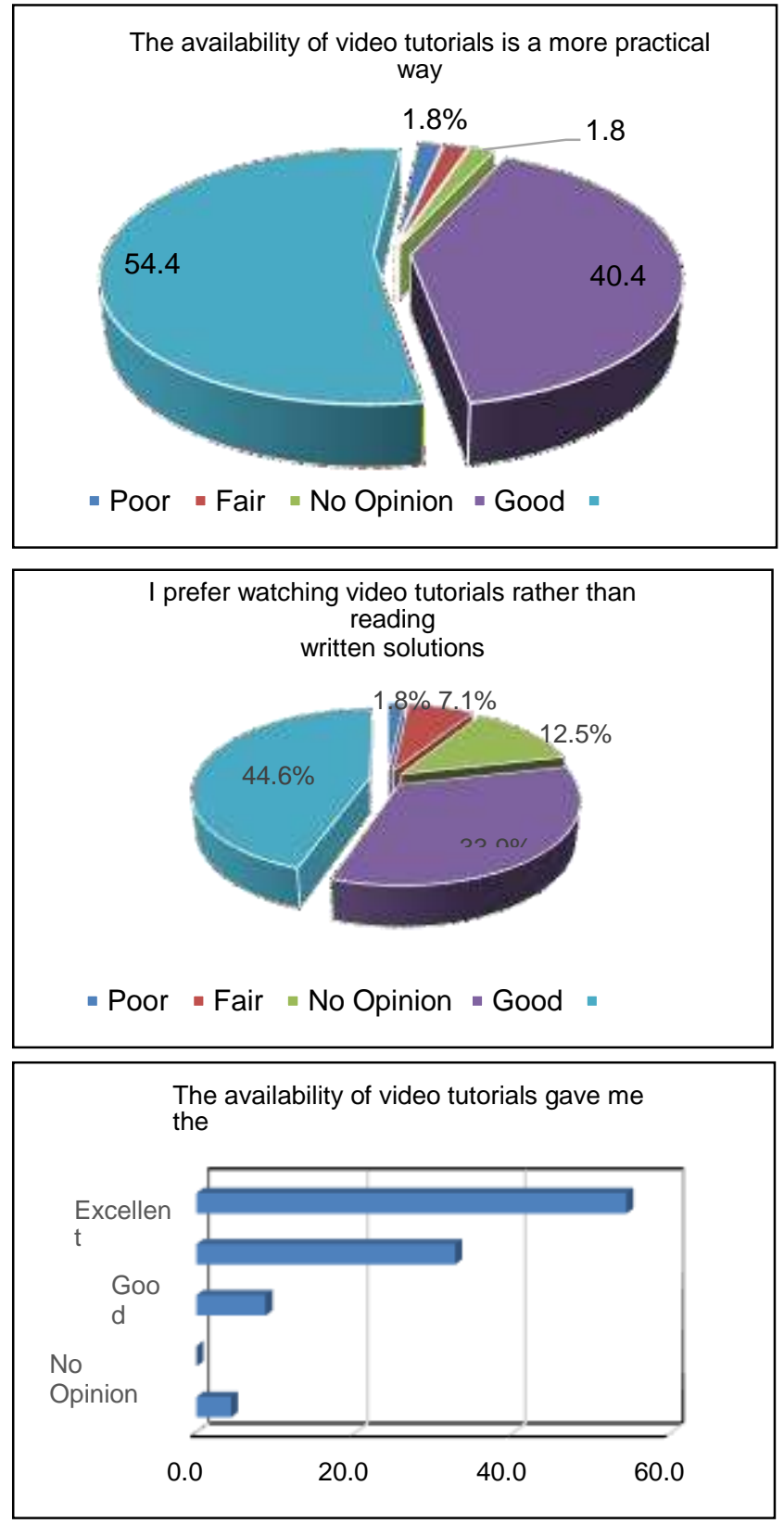

The video tutorials helped me to achieve the objectives

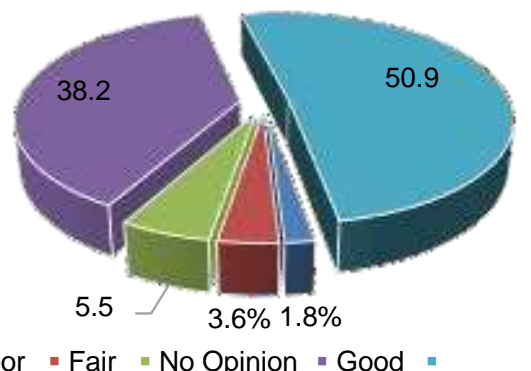

their learning and helped to prepare them for the exam.
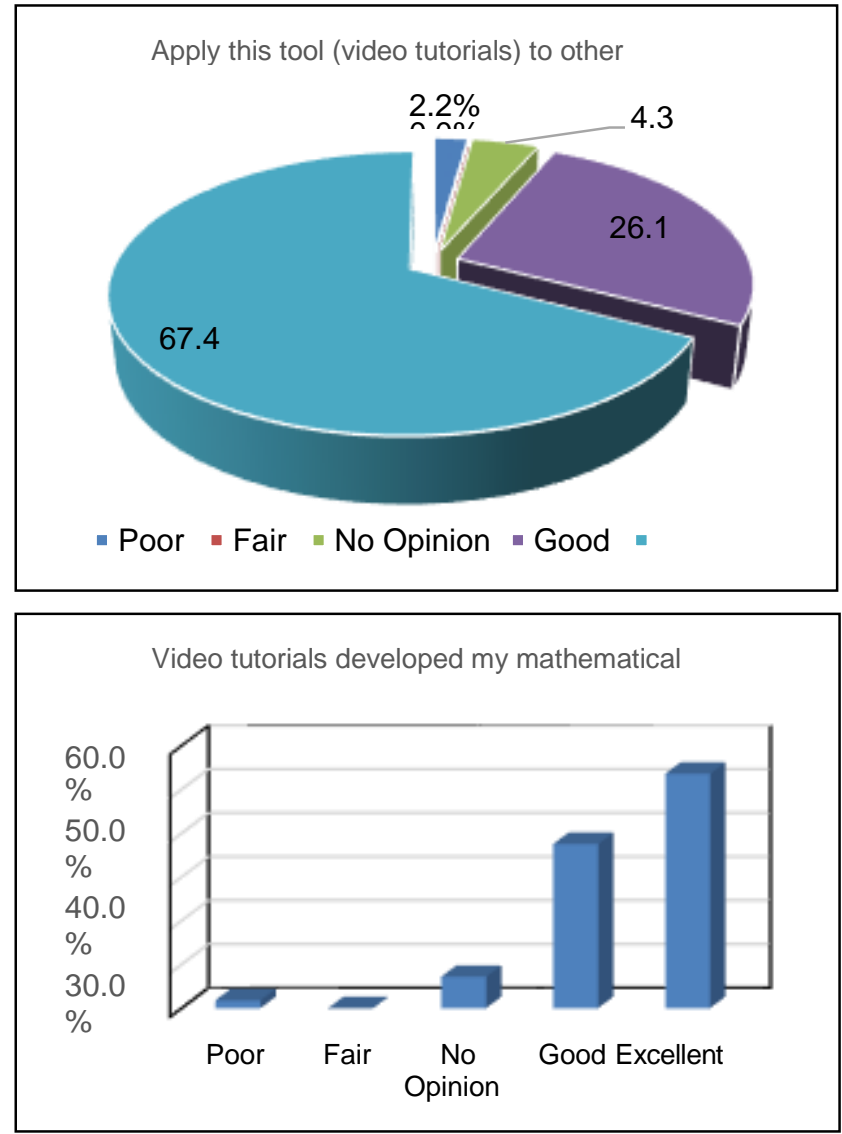

Video tutorials increased my motivation to study

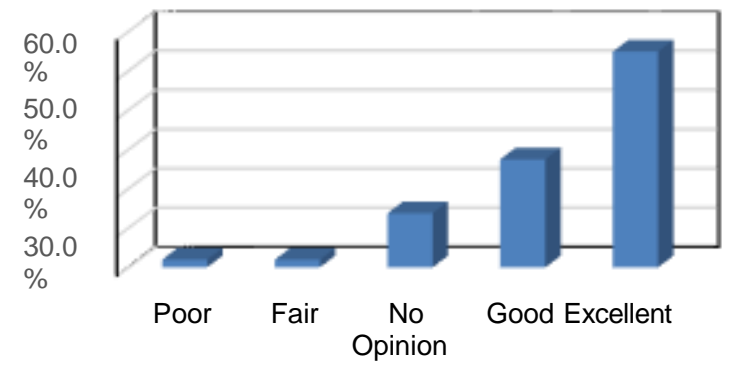

Video tutorials facilitate my topic thinking and solving

$180 / 18 \% \ldots$

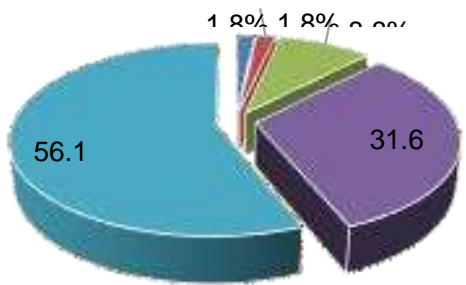

- Poor " Fair " No Opinion - Good "

Figure 3: Student's Responses to Different Questions of Impact of VT on Learning 


\section{International Conference on Advanced Research in Teaching and Education}

Moreover, only $35 \%$ of the students responded to the section of provide any suggestion to make the TEL more useful. $60 \%$ of the students who took part were happy about the current format of the VT, the remaining $40 \%$, their responses included enhance the technical side of VT such as reducing the size for easy downloading, provide more voice instructions by giving more details about the solution and finally apply the VT to other modules.

\section{CONCLUSIONS}

The main findings and conclusions of this study are listed below:

$>$ Data revealed that around $80 \%$ of the student's learning preferences, their selections were based on visual, written or spoken explanation, solving problems/using mathematical relationships and step aby step approach to get understanding as a direction of learning.

$>65 \%$ of the students spent more than $40 \%$ of their revision time on watching the video tutorials as a revision material and the remaining $35 \%$ of the students spent between 10 to $30 \%$.

$>$ Around $85 \%$ of students felt that using the suggested TEL in the tutorial sessions helped them learn the course materials, feel more engaged, confident with how to deal with topic, support independent learning, and used as assessing tool for assessing their learning and prepare them for the exam.

$>$ Quality of the recorded tutorial videos is important to attract students to watch these videos.

$>$ Finally, Tutorial videos support the Students 'Centred Learning and the diversity of the students' background through the choice of how and when to learn the knowledge. Providing tutorial videos as an extra teaching tool, the students will have the choice to select a suitable teaching tool to support their learning.

\section{REFERENCES} mathematical explanation through audiographic technology. Computers and Education, 38(1-3), 137149 (2002).

[5] Nathaniel D. Poling. Collaboration, teamwork, and team cohesion in a starcraft 2 digital game-based course. A dissertation presented to the graduate school of the University of Florida in partial fulfilment of the requirements for the degree of doctor of philosophy, University of Florida (2013).

[6] Heilesen, S. B. What is the academic efficacy of podcasting? Computers and Education, 55(3), 10631068 (2010). 